\title{
Total knee replacement in Osteogenesis Imperfecta: a case report and review of the literature
}

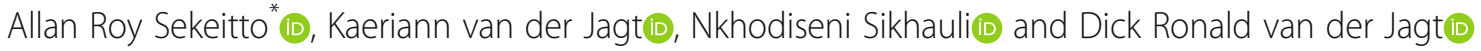

\begin{abstract}
Background: A review of the literature revealed that only 9 total knee replacements were performed on patients with osteogenesis imperfecta $(\mathrm{OI})$, with one being a revision procedure of a periprosthetic fracture. Of the 9 primary procedures, all used cemented prostheses, and 3 patients had an osteotomy at the same procedure. Our patient required a hinged prosthesis because of collateral ligament incompetence and is the first such case reported in the literature.

Case presentation: Presented here is a total knee replacement performed on a 52-year-old patient with osteogenesis imperfecta $(\mathrm{Ol})$ who injured her left knee and ruptured her anterior cruciate ligament. Her right knee suffered from severe degenerative changes with an incompetent medial collateral ligament. It was decided to replace the right knee before addressing the left knee injury. A hinged revision prosthesis was used. The smallest components available were used because of the small anatomical bony dimensions.

Conclusion: This is the first reported case of a hinged prosthesis and highlights the soft tissue component of osteogenesis imperfecta. We also highlight the technical problems with these patients, including mal-alignment, small bony dimensions and bone fragility.
\end{abstract}

Keywords: Osteogenesis imperfecta, Total knee replacement, Arthroplasty, Hinged prosthesis

\section{Background}

Osteogenesis Imperfecta (OI) is a rare congenital disorder that affects connective tissue. It presents in 1 in 20,000 births and is caused by a genetic alteration resulting in abnormal collagen structure, ossification and mineralisation. This condition leads to various orthopaedic manifestations and inherent coagulation defects due to abnormal collagen within the endothelial capillary bed $[1,2]$.

Amongst the described orthopaedic manifestations are protrusio acetabuli, trefoil pelvis, ligament laxity, osteoporosis, fragile bone, malunion, non-union and limb deformities. The distortion of the normal anatomy with significance to a total knee arthroplasty is the femur that

\footnotetext{
* Correspondence: sekeitto@yahoo.com

Arthroplasty Unit, Division of Orthopaedic Surgery, Charlotte Maxeke

Johannesburg Academic Hospital, University of the Witwatersrand, 7 York

Road, Parktown, Johannesburg, South Africa
}

often has a shepherd-crook's deformity [3]. OI patients, thanks to modern medical advances, have a virtually normal life span [4]. The joint laxity and fractures with secondary joint degeneration leads to hip and knee osteoarthrosis requiring joint arthroplasty [1].

Patients present with a broad spectrum of severity, ranging from intrauterine death to milder forms only diagnosed later in adulthood. The long bones are prone to bowing, fracture, subsequent malunion and non-union, with associated narrowing of the intramedullary canal. Adults present with early severe arthritis, long bone deformities and scoliosis [5].

Here we present a case study of a patient with OI who underwent a total knee arthroplasty.

(c) The Author(s). 2021, corrected publication 2021. Open Access This article is licensed under a Creative Commons Attribution 4.0 International License, which permits use, sharing, adaptation, distribution and reproduction in any medium or format, as long as you give appropriate credit to the original author(s) and the source, provide a link to the Creative Commons licence, and indicate if changes were made. The images or other third party material in this article are included in the article's Creative Commons licence, unless indicated otherwise in a credit line to the material. If material is not included in the article's Creative Commons licence and your intended use is not permitted by statutory regulation or exceeds the permitted use, you will need to obtain permission directly from the copyright holder. To view a copy of this licence, visit http://creativecommons.org/ licenses/by/4.0/. 


\section{Case report}

A 52-year-old female patient with OI had recently injured her left knee, rupturing her anterior cruciate ligament (ACL). She had pre-existing degenerative changes in her right knee with a deficient medical collateral ligament (MCL) of clinical grade 3, which had been symptomatic for 2 years prior to her fall (Figs. 1 and 2). We opted to perform a right total knee replacement before addressing the left knee injury. This would provide her with an immediate stable right limb prior to addressing her left knee.

A Nextgen Rotating Hinge Knee (ZimmerBiomet $\left.{ }^{\circ}\right)$ hinged prosthesis was used because of her incompetent MCL (Fig. 3). The smallest components available were used because of her small anatomical bony dimensions. The OI population tend to experience growth retardation and standard implant sizes are generally over-sized for these patients. This necessitates pre-operative planning in the form of templating to ensure the specific

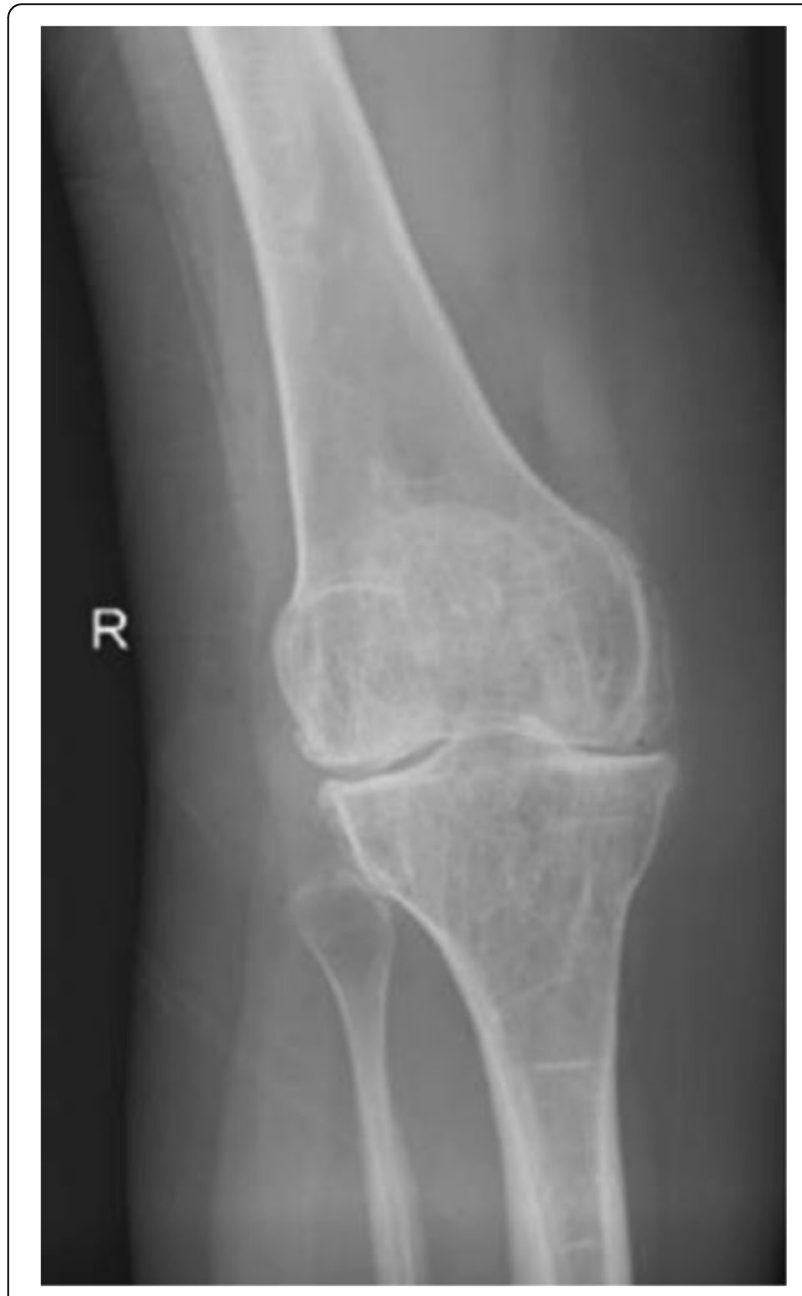

Fig. 1 A preoperative AP radiograph demonstrating the degenerative changes in the knee

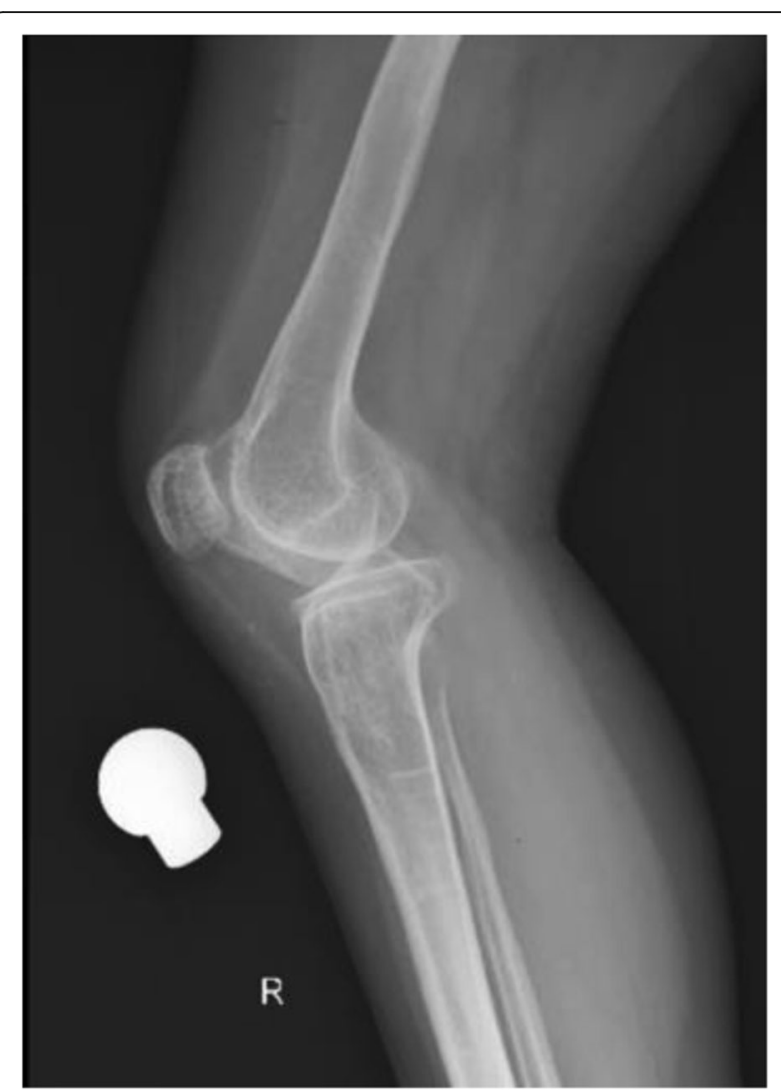

Fig. 2 A preoperative lateral radiograph demonstrating the degenerative changes in the knee

implant sizes are available for the patient. In the absence of such implants, patient-specific implants and cutting guides should be considered for outlier cases [5]. The initial postoperative course was uneventful. The patient mobilised slowly though. She had poor flexion at 6 weeks and a gentle manipulation was performed cognizant of the inherent dangers. She is currently at 2year post-op with full extension and flexion to 110 degrees. The patient-reported outcome measures improved as follows: her visual analogue score (VAS) was 7/10, 3/ 10 and $2 / 10$ before, 6 and 24 months after surgery respectively. The Western Ontario and McMaster Universities Osteoarthritis Index (WOMAC) knee score was 36.4, 59.4 and 86.4 before, 6 and 24 months after surgery respectively. She continued to wear a brace on left knee as she was reluctant to undergo an ACL reconstruction.

\section{Discussion}

A review of the literature revealed that only 9 total knee replacements were performed on OI patients (Table 1). The 9 primary procedures, all employed cemented prostheses, and 3 patients needed an osteotomy at the same procedure. Two cases received revision components, and one was due to an intra-operative periprosthetic fracture 


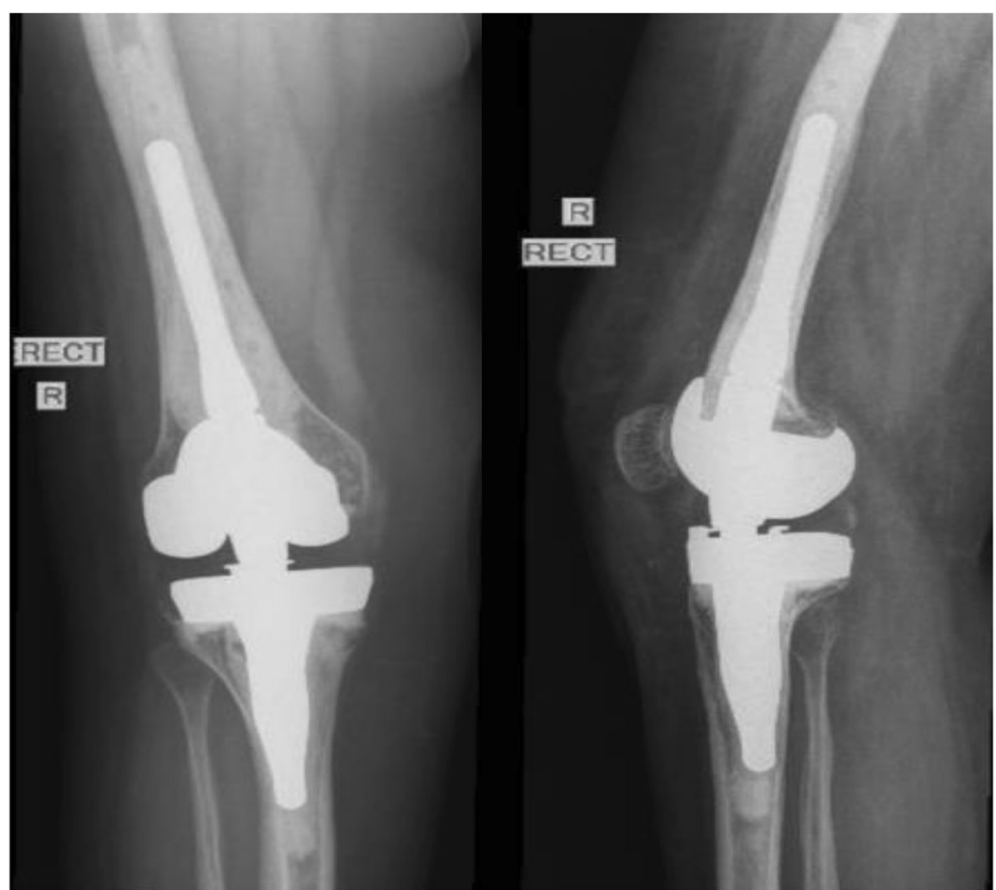

Fig. 3 A postoperative AP and lateral radiograph of the knee demonstrating the cemented hinged prosthesis

that necessitated the revision of the tibial component to a stemmed component with augments during the primary procedure. With the second case, the revision was performed with a total femur component and a stemmed tibial component due to a failed hip femoral component, and this failure is due to perforation through the trochlea. The constraint of the prosthesis in the literature is shown in Table 1. Five posterior stabilised, three cruciate retaining and a single hinge implants were used in the total knee replacements. All the procedures were indicated for secondary osteoarthritis except the single case of a total femur replacement with a hinged prosthesis, with the patient having developed a complication related to a previous failure of hip femur revision. The average age was 50 years, which was similar to the age of our patient. The case studies reported good pain relief and improved functional outcomes in the patients that underwent total knee replacements $[4,5]$.

\section{Component sizing}

Nishimura and colleagues [6] presented a case for whom they had planned to use posterior constrained

Table 1 Published articles with total knee replacements for Osteogenesis Imperfecta

\begin{tabular}{|c|c|c|c|c|}
\hline Article & No. of patients & Age & Indication & Implants \\
\hline \multirow{2}{*}{$\begin{array}{l}\text { Papagelopoulos } \\
\text { et al. [4] }\end{array}$} & \multirow[t]{2}{*}{2} & $54, F$ & Bilateral Osteoarthritis & Posterior-stabilised $\times 2$ \\
\hline & & $46, F$ & Osteoarthritis & Cruciate-retaining \\
\hline Nishimura et al. [6] & 1 & $53, M$ & Osteoarthritis & Cruciate-retaining \\
\hline \multirow[t]{2}{*}{ Wagner et al. [5] } & \multirow[t]{2}{*}{2} & $46, M$ & Osteoarthritis & $\begin{array}{l}\text { Cruciate-retaining, femur and tibia osteotomies (femur retrograde } \\
\text { intramedullary nail and flexible titanium intramedullary nails) }\end{array}$ \\
\hline & & $37, M$ & Bilateral Osteoarthritis & $\begin{array}{l}\text { Right: Posterior-stabilised, femur and tibia osteotomies (flexible } \\
\text { titanium intramedullary nails) } \\
\text { Left: Posterior-stabilised, femur and tibia osteotomies (flexible } \\
\text { titanium intramedullary nails and dynamic compression plates) } \\
\text { Left Conversion: tibia intraoperative periprosthetic fracture, tibia } \\
\text { component revised cemented tibia } 80 \mathrm{~mm} \text { stem and } 10 \mathrm{~mm} \\
\text { augment during the primary procedure }\end{array}$ \\
\hline Brand et al. [7] & 1 & $69, F$ & Osteoarthritis & Posterior-stabilised \\
\hline Sanz-Ruiz et al. [1] & 1 & $65, F$ & $\begin{array}{l}\text { Hip femoral stem perforated } \\
\text { through trochlea }\end{array}$ & Total femur replacement, hinged prosthesis and stemmed tibia \\
\hline
\end{tabular}


components for the total knee replacement. They found the posterior stabilised components was too large for their patient and had to switch to a cruciate retaining prosthesis. This was similar to our case where the smallest components were used [4]. In our case, we used the smallest components available to perform the total knee replacement. The patient population with OI tend to experience growth retardation and standard implant sizes are generally found to be too big for these patients. This necessitates meticulous pre-operative planning in the form of templating using sizing markers on the planning radiographs to ensure the specific implant size is available for the patient. In the absence of such implants, patient-specific implants and cutting guides should be considered for outlier cases [7].

\section{Hinged- prothesis}

Our case study is the first in the literature to describe a case of a primary total knee replacement performed with a hinged prosthesis for OI-related osteoarthritis. Sanz-Ruiz et al. presented a case of a total femur replacement and hinged knee with a stemmed tibia secondary to a hip femoral revision component that failed and perforated the femoral trochlea (1). This was due to the poor bone quality in OI patients. The generalised laxity presents another challenge to total knee arthroplasty in obtaining a stable knee postoperatively. In patients with severe coronal deformities, the soft tissues are lax, depending on whether the convexity lies on the medial or lateral side and this may result in such tissue imbalance. The milder soft tissue imbalances can be managed with soft tissue release intraoperatively. However, constrained implants should be considered for the deformities of more than 20 degrees [7, 8]. In our case, we performed a total knee replacement with a hinged prosthesis due to the patient's incompetent medial collateral ligament.

\section{Long bone deformities}

Long bone bowing and the resultant deformities pose an alignment challenge and the mechanical axis and angular deformities must be evaluated preoperatively [7]. The femur presents with $46-86 \%$ anterolateral bowing and associated $27-86 \%$ anterior bowing of the tibia [4].

The management options are either an extra-articular osteotomy [5] or an adjusted intra-articular resection [4]. These procedures can be proposed at the time before total knee placement or as a staged procedure. The intra-articular resection has the advantage of reducing second site complications. Nonetheless, this modality is limited by the extent of the presenting deformity. In their series of three total knee replacements with concurrent osteotomies, Wagner et al. [5], had a single case of tibia non-union 11.5 months after the procedure, which was managed with open reduction and internal fixation and augmented with iliac crest autograft. The use of intra-medullary referencing in patients with deformity or a narrow canal with deformity may lead to iatrogenic fractures and recommendations have been made for extramedullary referencing techniques, patientspecific cutting blocks or navigation assistance $[6,7]$.

\section{Poor bone quality}

The poor bone quality results in complications. Wagner and colleagues [5] reported intraoperative fractures in their series, including a non-displaced fracture of the patella and a compression fracture of the proximal tibia that required revision to a stemmed tibial component with augments. The patient should be handled carefully especially during trialing and definitive component placement to prevent iatrogenic fractures [7]. An extension stem of the tibial component could help address osteopenia in the metaphysis [7]. The osteopenia may lead to thinned patellae, which can fracture and therefore the literature recommends against patella resurfacing [6, 7]. A single case of patella fracture was reported in the literature [5]. In our case, we did not resurface the patella.

\section{Anaesthesia and theatre set up}

The literature recommends that during theatre settingup, a well-padded operating table should be used to the protect the patient from injury [7] since deformities, common in these patients, can easily lead to pressure sores. Regional anesthesia is preferred but is often contraindicated because of anatomical anomalies such as scoliosis. In cases where general anaesthesia is elected, fiberoptic endoscopy-aided intubation was used to avoid cervical spine fractures or injury due to instability which should be screened for preoperatively [4, 7]. The patients are at risk of chipping of teeth, mandibular fractures or may have airway abnormalities secondary to a large tongue or a short neck [4]. In our case, the patient had a spinal anaesthesia supplemented by a general anaesthetic.

\section{Conclusion}

There is a paucity of literature on total knee replacement in OI patients. The improved medical care has improved patients' life span. We foresee an increase in the demand for arthroplasty in this population. The importance of understanding the underlying disease, component sizing, adequate constraint, management of long bone deformities, mitigation of iatrogenic injury and anaesthetic risk must be addressed for a safe surgery and a satisfactory outcome. Total knee replacement should be part of the long term management of OI patients.

\section{Abbreviations}

ACL: Anterior cruciate ligament; $\mathrm{MCL}$ : Medical collateral ligament: Ol: Osteogenesis imperfecta 


\section{Acknowledgements}

Not applicable.

\section{Authors' contributions}

DR made substantial contribution to conception, interpretation of data and substantially revised the manuscript. KV contributed to the acquisition, analysis and interpretation of data. NS substantially contributed to the revision of the manuscript. AR made substantial contribution to the acquisition, analysis and interpretation of data and was a major contributor to the preparation of the manuscript. The authors read and approved the final manuscript.

\section{Funding}

Not applicable.

\section{Availability of data and materials}

The datasets used and analysed during the current study are available from the corresponding author on reasonable request.

\section{Ethics approval and consent to participate}

Ethics approval and patient consent were obtained.

\section{Consent for publication}

Consent was obtained.

\section{Competing interests}

DR received personal fees from Smith+Nephew. The authors declare that they have no competing interests.

Received: 2 July 2020 Accepted: 14 December 2020

Published online: 02 April 2021

\section{References}

1. Sanz-Ruiz P, Villanueva-Martinez M, Calvo-Haro JA, Carbo-Laso E, VaqueroMartin J. Total femur arthroplasty for revision hip failure in osteogenesis imperfecta: limits of biology. Arthroplast Today. 2017;3:154-9. https://doi. org/10.1016/.jartd.2017.01.001.

2. Liporace F, Yoon R, Frank M, Maurer J, Gaines R. Single-stage Total hip Arthroplasty and fracture fixation for a both column Acetabular fracture in type I Osteogenesis Imperfecta. Injury. 2011;42:1184-7. https://doi.org/10. 1016/j.injury.2011.05.008.

3. Ramaswamy R, Kosashvili Y, Camcron H. Bilateral total hip replacement in OI with hyperplastic callus. J Bone Joint Surg Br. 2009;91:812-4. https://doi.org/ 10.1302/0301-620X.91B6.22061.

4. Papagelopoulos P, Morrey B. Hip and Knee Replacement in Osteogenesis Imperfecta. J Bone Joint Surg Am. 1993;75:573-80. https://doi.org/10.2106/ 00004623-199304000-00011.

5. Wagner R, Luedke C. Total Knee Arthroplasty With Concurrent Femoral and Tibial Osteotomies in Osteogenesis Imperfecta. Am J Orthop. 2014;43:37-42.

6. Nishimura A, Hasegawa M, Kato K, Fukuda A, Sudo A, Uchida A. Total knee arthroplasty in osteogenesis imperfecta: Case report. Knee. 2008;15:494-6. https://doi.org/10.1016/j.knee.2008.07.005.

7. Brand J, Tyagi V, Rubin L. Total knee arthroplasty in osteogenesis imperfecta. Arthroplast Today. 2018;5(2):176-80. https://doi.org/10.1016/j. artd.2018.09.006.

8. Ranawat AS, Ranawat CS, Elkus M, Rasquinha VJ, Rossi R, Babhulkar S. Total knee arthroplasty for severe valgus deformity. J Bone Joint Surg Am. 2005; 87(Suppl 1):271-84. https://doi.org/10.2106/JBJS.E.00308.

\section{Publisher's Note}

Springer Nature remains neutral with regard to jurisdictional claims in published maps and institutional affiliations.

Ready to submit your research? Choose BMC and benefit from:
- fast, convenient online submission
- thorough peer review by experienced researchers in your field
- rapid publication on acceptance
- support for research data, including large and complex data types
- gold Open Access which fosters wider collaboration and increased citations
- maximum visibility for your research: over 100M website views per year
At BMC, research is always in progress.
Learn more biomedcentral.com/submissions

